\title{
The rare deer of Cedros Island, Mexico
}

\author{
Anthony Povilitis and Enrique Ceballos
}

The mule deer endemic to Cedros Island, off Baja California, was believed to be endangered until a survey in 1980 revealed that around 300 still remained. The authors carried out a follow-up survey in $\mathbf{1 9 8 5}$ in order to discover whether the status of the deer had changed and to devise a method for the long-term monitoring of its population.
Mule deer Odocoileus hemionus of westem North America range widely from south-east Alaska to central Mexico (Wallmo, 1981). Of nine subspecies, one-the Cedros Island deer O.h. cerrosensis of Baja California, Mexico-is listed in The IUCN Mammal Red Data Book (Thomback and Jenkins, 1982). This race of mule deer differs from adjacent mainland races in the

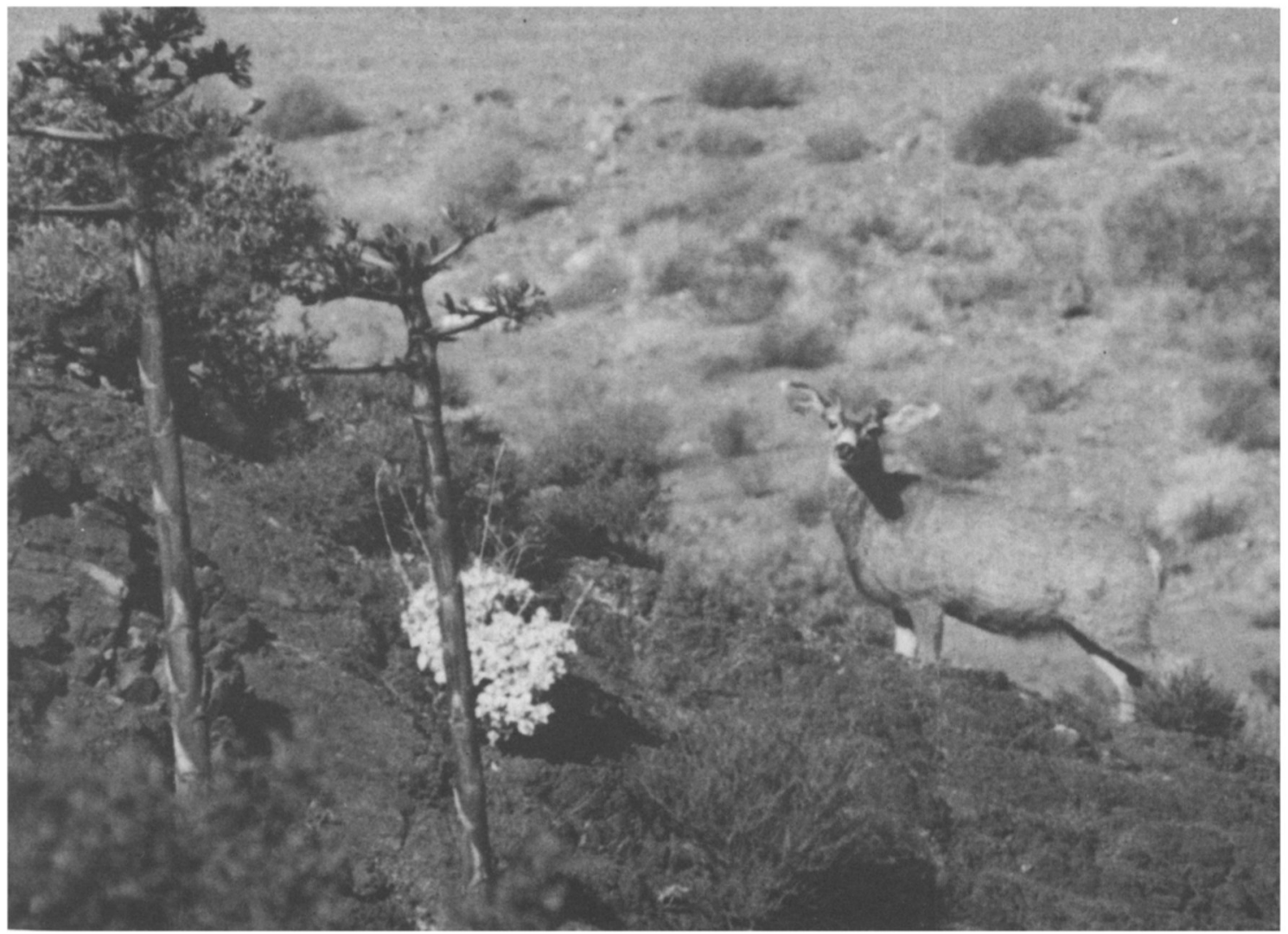

A Cedros Island mule deer buck with new antler growth (A. Povilitis).

Rare deer of Cedros Island, Mexico 
extreme paleness of the summer pelage and in having underparts, which are otherwise white, washed with buff (Cowan, 1936). It is also believed to be smaller in size.

Until recently, the Cedros mule deer was considered endangered or perhaps extinct (Huey, 1964; Cowan and Holloway, 1978; Thornback and Jenkins, 1982). Archaeologists, botanists and geologists working on the island over the past 15 years have rarely seen deer ( $T$. Banks, pers. comm.). Local residents generally were unaware of their presence and, in some cases, believed them to be strange goats or gazelle-like animals (Perez-Gil, 1981). In the late 1970s, the Mexican Wildlife Service estimated 69-185 deer (Salas, 1979; Perez-Gil, 1981).

Was the Cedros mule deer as scarce as it seemed? In 1980 Ramón Perez-Gil Salcido, a graduate student, spent four months on the island in order to find out. Based on pellet group counts, he estimated a population of $288 \pm 185$ deer, and found the animals absent only from the southern third of the island. Yet Cedros deer seemed 'vulnerable', since they were illegally, though apparently lightly, hunted, and faced potential competition for food from feral goats and burros.

Our survey of February-March 1985 served as a follow-up to Perez-Gil's work. We wanted to determine whether the deer's status had changed since 1980 , and also to devise a method useful for monitoring its population.

\section{Cedros Island}

Cedros Island, the largest of Mexico's Pacificcoast islands ( $360 \mathrm{sq} \mathrm{km}$ ), was once part of peninsular Baja California, having been cut off by the sea, presumably during the last two million years (Osorio-Tafall, 1948). It is a mountainous island with steep slopes, exceptionally loose rock, and peaks reaching $1000-1300 \mathrm{~m}$. Desert scrub occurs over most of it, although chaparral and small stands of pine Pinus muricata thrive where moisture allows. Cacti are common. The term 'Cedros' (cedars in English) was originally applied to the California juniper Juniperus californica, which occurs scattered or in small groves.

Terrestrial mammals endemic to Cedros Island include two species, the Cedros pocket mouse 112
Perognathus anthonyi and wood rat Neotoma bryanti, and in addition to the Cedros mule deer, two subspecies of mainland animals, the bush rabbit Sylvilagus bachmani cerrosensis and white-footed mouse Peromyscus eremicus cedrosensis (Huey, 1964). How these animals became established on the island is unclear. However, in the case of the mule deer, the absence of other large native mammals that occur on the adjacent peninsula suggests that it was brought to Cedros by local Indians, to whom deer were of ceremonial significance (Aschmann, 1967). Two villages, with a total population of about 6000 people, are located on the relatively flat south-east corner of Cedros. Most people are associated with a fish cannery or salt-loading wharf, where mainland salt is loaded on to tankers. With the exception of local fishermen, very few people venture into other areas of the island.

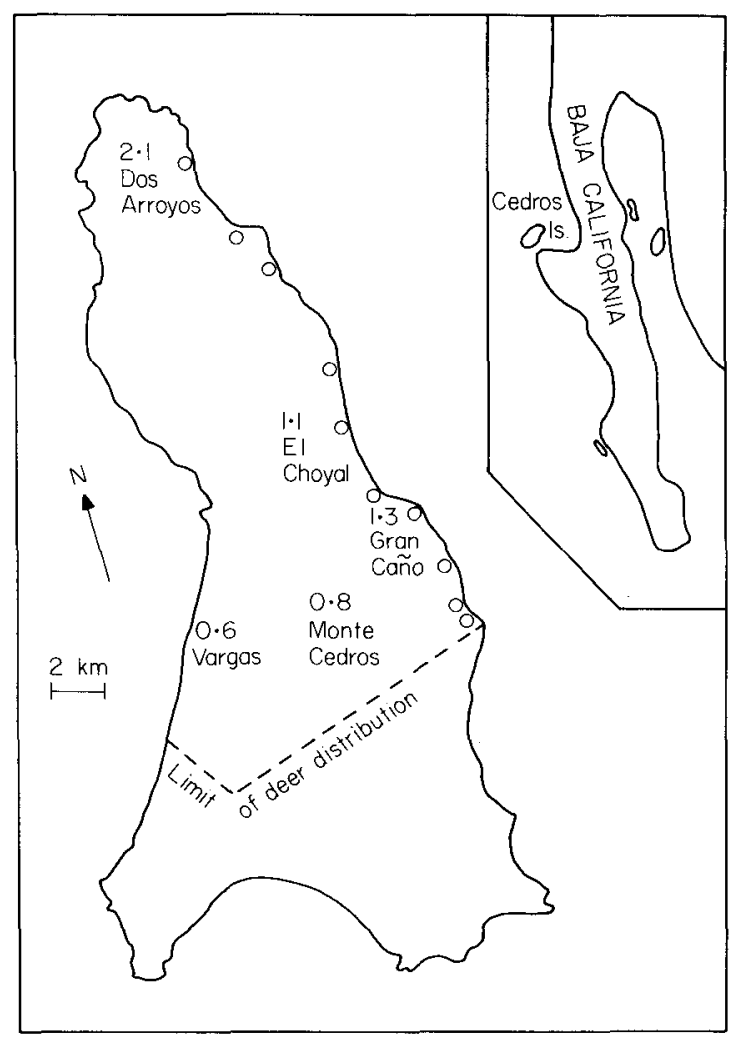

Figure 1. The estimated density of deer per sq $\mathrm{km}$ for five sample areas on Cedros Island, Mexico, 1985. Circles indicate sites examined for signs of deer.

Oryx Vol 20 No 2. April 1986 


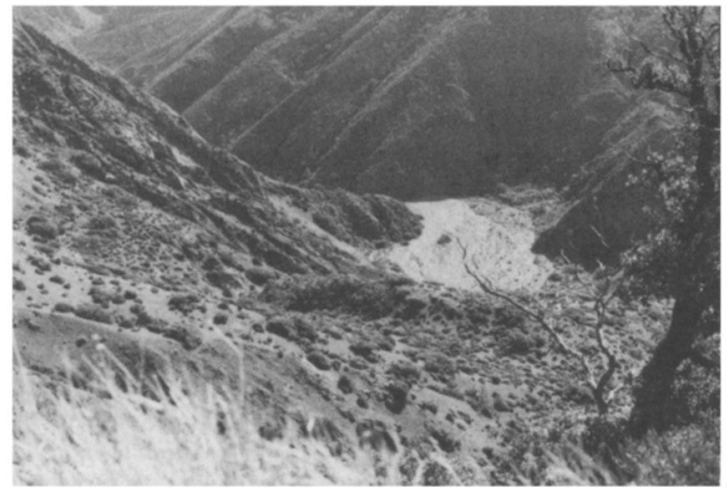

Signs of mule deer were most commonly found on rolling terrain along major ridges and lower slopes (A. Povilitis)

\section{The survey}

Five sample areas on Cedros Island were selected: Dos Arroyos (285 ha), El Choyal (356 ha), Gran Caño (355 ha), Monte Cedros (598 ha) and Vargas (316 ha). They included representative topography, were relatively accessible, and could be adequately covered on foot over a 1-2 day period.

We censused 22 deer within the $19 \cdot 1 \mathrm{sq} \mathrm{km}$ of the five sample areas, their density ranging from 0.6 deer per sq $\mathrm{km}$ at Vargas to $2 \cdot 1$ deer per sq $\mathrm{km}$ at Dos Arroyos (Figure 1). If deer occur at this range of density within their known distribution of 234 sq km, we estimate $276 \pm 168$ deer for the entire island. This figure closely approximates the 1980 estimate of $288 \pm 185$ deer.

In addition to the main sample areas, ten 2-4-ha sites along the island's east coast were inspected for deer signs. These 'check points', each located at the mouth of a canyon, were readily accessible by small boat and thus could easily be examined for deer.

Deer tracks and pellets were detected at all 10 points. In addition, deer occurred at localities between Gran Caño, Monte Carlo Cedros, and Vargas sampling areas. Only in the extremely dry and largely barren 'badlands' of Vargas did deer seem to be absent. These data indicate that deer remain widely distributed over the northern twothirds of the island.

\section{Behaviour}

Deer responded to us by immediately walking or

Rare deer of Cedros Island, Mexico running away on 14 out of 19 occasions ( 74 per cent). Only twice did a deer seem unconcerned. By contrast, in 1980 deer fled immediately in only 10 of 42 instances (24 per cent) and often ( 40 per cent of the time) seemed unconcerned by human presence. Unlike in 1980, they could seldom be observed at close range for more than ten minutes, or at times other than within 2.5 hours of sunrise. These sharp differences between studies suggest that hunting pressure has increased, even though in 1980 a much greater proportion of deer observations ( 73 per cent as opposed to 24 per cent) occurred in the less accessible northern third of the island, where deer would be less likely to be hunted. In any event, the deer we observed clearly behaved in a manner characteristic of hunted animals.

Cedros deer seem to prefer valley and ridgetop areas where benches, coves, saddles, basins, and flats offer gentle slopes amid otherwise rugged terrain. They favoured sites with tall ( $1 \mathrm{~m}$ or more) vegetation. Plant communities found on alluvial deposits along washes and at canyon mouths typically provided excellent cover.

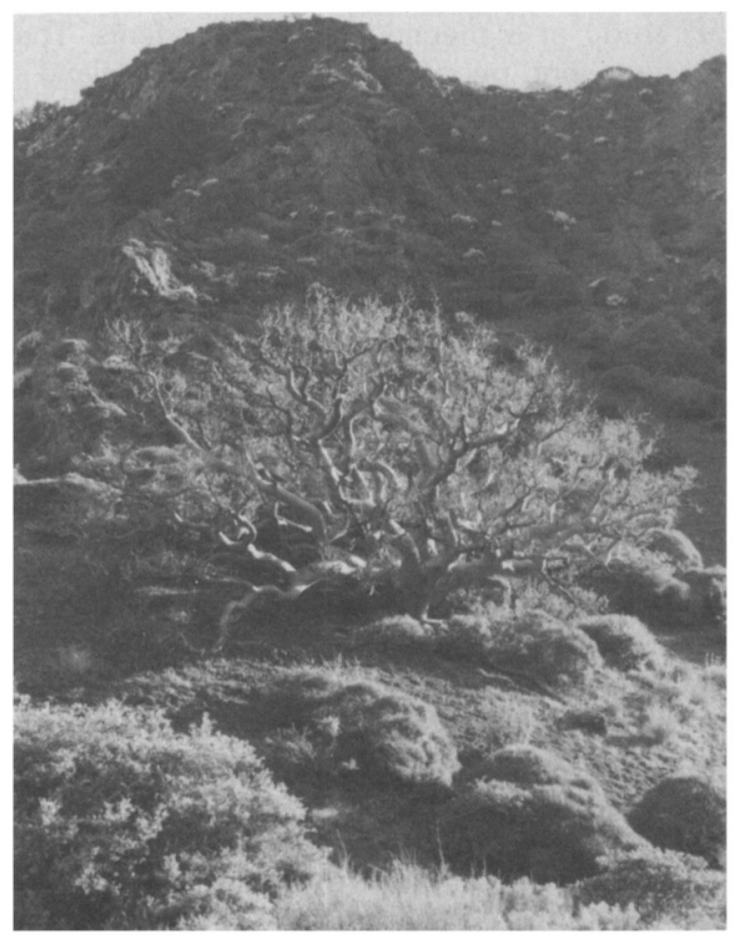

Elephant trees Pachycormus discolor. often several metres tall. provide excellent cover for Cedros deer (A. Povilitis) 


\section{Conservation}

The Cedros Island mule deer is listed as 'rare' in The IUCN Mammal Red Data Book, meaning that it is at risk because of its small population (Thornback and Jenkins, 1982). Threats to this subspecies include illegal hunting and problems associated with introduced species.

Several residents of Cedros told us that deer are routinely hunted, largely for sport, by persons from both the villages and from the mainland. Our observations on deer behaviour were consistent with this. Also, we found rifle shells (33 and 44 calibre) and a 12-gauge shotgun cartridge, which may have been used in deer hunting.

No recent signs of feral goats or burro were encountered during our study. These animals occur over portions of the south-eastern part of Cedros (Perez-Gil, 1981), but do not at present appear to be extending their ranges. Feral dogs are found only to the south of the deer's distribution, while feral cats, present throughout the island, do not pose a threat to the deer.

Authorities on Cedros Island invited us to discuss our study at a meeting of local residents. The concern that people showed for the island's wildlife impressed us. As a result of discussions that followed the meeting, we make the following recommendations.

(i) Non-residents using the island or its waters for recreation should be charged a small fee that would go toward the conservation of deer and other wildlife. (For example, northern elephant seal Mirounga angustirostris, California sea lion Zalophus californianus, and osprey Pandion haliaetus breed along the coast and are therefore particularly vulnerable to disturbance.) This fee could be collected during the required registration with the island's port authority.

(ii) Funds should be used to employ a wildlife warden, who would patrol the island to discourage harassment and poaching of wild species and to provide information for visitors.

(iii) The deer should be monitored, including a routine survey of the check points used in this study. Because of their accessibility, deer would probably disappear from these areas first if hunting increases. In addition, a periodic census within the 1985 sample areas could serve to monitor the 114 overall deer abundance on Cedros Island. Copies of aerial photos of these areas have been provided, along with a full report on the 1985 study, to the Dirección General de Flora y Fauna Silvestre of Mexico and to the IUCN Conservation Monitoring Centre in Kew, England.

\section{Acknowledgments}

Have Mule Will Travel Inc. of Alpine, California, USA made this project possible. Its Director, Mr Thomas Banks, who initiated the project, served as administrative director and kept us supplied with volunteers, provisions, and encouragement. We are indebted to Sr José Soria, his wife Jaunita, and his children for hosting us and our volunteers, for providing logistical support, and for being kind and generous in so many ways. We thank the many volunteers who assisted the project: we are especially grateful to Marcos Camacho. Patrick Fritzpatrick. Jim Mau and Carlos Plata for their extended service and hard work. Jim Mau and Maurey Brooks served as camp co-ordinators and cooks. We appreciated visits to the island on the project's behalf by Ramón Perez-Gil Salcido and Phil Robinson. Finally. we are most grateful to the Delegado of Cedros Island who approved of our project and to the many residents who helped make our stay a pleasant one.

\section{References}

Aschmann, H. 1967. The Central Desert of Baja Califomia Demography and Ecology. Manessier Publishing Company, Riverside, California.

Cowan. I. McT. 1936. Distribution and variation in deer (genus Odocoileus) of the Pacific coastal region of North America. Calif. Fish and Game, 22, 155-246.

Cowan. I. McT. and Holloway. C. 1978. Geographic location and current conservation status of the threatened deer of the world. In Threatened Deer. (ed. IUCN), pp. 11-22. Alden Press, Oxford.

Huey. L.M. 1964. The mammals of Baja California, Mexico. Trans. San Diego Soc. Nat. Hist. 13, 85-168.

Osorio-Tafall, B.F. 1948. La isla de Cedros, Baja California: Ensayo Monográfico. Soc. Mex. Geogr. y Estad. 66, 317 402.

Perez-Gil, R. 1981. A preliminary study of the deer from Cedros Island, Baja California, Mexico. Unpublished manuscript for thesis. University of Michigan, Ann Arbor.

Salas, A. 1979. Informe Suscinto Sobre Isla Cedros e Isla Guadalupe. Informe Interno. Dir. Gral. de Fauna Silvestre.

Thornback, J. and Jenkins, M. 1982. The IUCNMammalRed Data Book. Part 1. IUCN, Gland, Switzerland.

Wallmo, O.C. 1981. Mule and black-tailed deer distribution and habitats. In Mule and Black-Tailed Deer of North America. (ed. O.C. Wallmo), pp. 1-25. University of Nebraska Press, Lincoln.

A. Povilitis, Wildlife Campaigns, Inc. PO Box 416, Boulder CO 80306. USA.

E. Ceballos, Escuela Superior de Ciencias Biologias. Universidad Autonoma de Baja California, Baja Califormia, Ensenada, BC, Mexico. 